\title{
ANALISIS PEMODELAN 3D CANDI JAWI MENGGUNAKAN WAHANA QUADCOPTER DAN TERESTRIAL LASER SCANNER (TLS)
}

\author{
Yuwono*1 $^{*}$ Danar Guruh Pratomo², Agung Budi Cahyono ${ }^{3}$, Yulita Eka Rana Mulyono ${ }^{4}$, \\ Teknik Geomatika, Fakultas Teknik Sipil, Lingkungan, dan Kebumian, Institut Teknologi Sepuluh Nopember (ITS) \\ Jl. Arief Rahman Hakim, Surabaya 60111 Indonesia \\ e-mail: yuwono@geodesy.its.ac.id
}

\begin{abstract}
Abstrak
Perkembangan teknologi masa kini semakin beragam dan terus berkembang. Mengikuti perkembangan teknologi, peralatan survei, dan pemetaan terus berinovasi dari tingkat manual sampai dengan menekan satu tombol semua selesai. Hal ini merupakan suatu keuntungan sekaligus kemudahan yang dapat dimanfaatkan. Salah satu contoh perkembangan teknologi alat survei dan pemetaan ialah munculnya quadcopter dan Terestrial Laser Scanner (TLS). Belakangan ramai diketahui quadcopter dan TLS bukan hanya untuk pemetaan terestris saja, melainkan juga dapat dimanfaatkan sebagai alat akusisi data untuk keperluan pemodelan 3D suatu objek. Keberadaan alat ini sangat membantu untuk dokumentasi dan pengarsipan. Kedua alat tersebut dipraktikkan untuk mengukur bangunan cagar budaya yang bertujuan agar diperoleh model tiga dimensi dengan tujuan akhir hasilnya dapat disimpan sebagai arsip, digunakan sebagai media penelitian dan dapat dimanfaatkan jika sewaktu-waktu bangunan tersebut rusak atau roboh dan memerlukan rekonstruksi ulang oleh Dinas Kebudayaan dan Pariwisata. Pengukuran dengan dua alat tersebut dikerjakan pada sebuah candi di Jawa Timur yang dikenal sebagai Candi Jawi. Pengukuran Candi Jawi meliputi pemotretan dengan quadcopter, pengamatan Ground Control Point (GCP), pengukuran Independent Check Point (ICP), dan pemindaian candi dengan Terestrial Lasser Scanner (TLS). Hasil yang diperoleh ialah model tiga dimensi hasil data quadcopter RMSe X, Y, Z sebesar 0,017 meter, 0,017 meter, dan 0,018 meter. Sementara besar nilai RMSe model tiga dimensi hasil olahan point cloud TLS untuk X, Y, dan Z ialah 0.056 meter, 0,066 meter, dan 1,44 meter. Kedua model dari kedua alat menunjukkan hasil yang relatif kecil karena bernilai kurang dari 0,5 meter dan memenuhi syarat Level of Detail (LoD) 3 untuk konsep visualisasi eksterior model bangunan, kecuali pada nilai Root Mean Square Error (RMSe) Z model 3D data point cloud TLS.
\end{abstract}

Kata Kunci-model 3D, data quadcopter, data TLS

\begin{abstract}
Survey and mapping technology nowadays has been develop variously. This provide many easiness but also testing is required to maximize its potential. Quadcopter and Terrestrial Laser Scanner (TLS) are products of technology development. The application of both technology are for terestrial mapping and 3D modeling purposes. In this research both equipments is used for data acquisition of Jawi Temple, located in East Java. The goal of this activity is to obtain the 3D model of Jawi temple as a historical building document that can help Department of Tourism, Art, and Culture in case the temple is collapsed or damaged. Data acquisition activities include photography, GCP observation, ICP measurement, and TLS scanning. The result of 3D model from Quadcopter image data has RMSe $X, Y, Z$ about 0.017 meter, 0.018 meter, and 0.018 meter. Meanwhile 3D model from TLS has RMSe X 0.062 meter, RMSe Y 0.231 meter, and RMSe Z 1.464 meter. Both 3D models are acceptable for LoD 3 (accuracy under 0.5 meter), except RMSe $Z$ for $3 D$ model of TLS data. Next, this method can be applied for other historical building for preserving the nation's heritage and culture.
\end{abstract}

Keywords: 3D model, Quadcopter data, Laser Scanner data

\section{PENDAHULUAN}

Bangunan Cagar Budaya menurut UU Nomor 11 Tahun 2010 Tentang Cagar Budaya Pasal 1 Ayat 1 ialah suatu wujud dokumen yang memiliki peran penting terkait perjalanan bangsa Indonesia. Candi termasuk bangunan cagar budaya yang dimiliki Indonesia yang telah ada sejak jaman kerajaan dan tersebar di Pulau Jawa. Sebagai wujud dokumen yang memiliki peran penting yaitu berfungsi untuk memperpanjang ingatan bangsa, baik menyangkut pelaksanaan kegiatan, peraturan, atau pelaku sejarah. Karena pentingnya manfaat dokumen, maka kegiatan dokumentasi cagar budaya menjadi salah satu bagian pekerjaan pelestarian terhadap cagar 
budaya yang tidak dapat diabaikan. Dengan adanya dokumenatasi yang baik, maka data tentang Cagar Budaya dapat selalu dilestarikan dan dimanfaatkan, meskipun benda fisiknya sudah hilang atau musnah. Namun, karena masih tersimpan dokumen yang lengkap misalnya dalam bentuk deskripsi, gambar, foto, atau film maka data tentang cagar budaya tersebut masih dapat dimanfaatkan (Sutopo, 2014)

Oleh karena pentingnya keberadaan sebuah dokumen, akan dilakukan pendokumentasian pada salah satu candi di Jawa Timur yang terletak di kaki Gunung Welirang . Tepatnya di Desa Candi Wates, Kabupaten Pasuruan, dengan jarak sekitar 31 km dari Kota Pasuruan yang diyakini sebagai tempat pemujaan. Kegiatan pemodelan candi dimaksudkan selain untuk dokumentasi, juga agar memperoleh manfaat dalam hal pendidikan dan pariwisata (Hidayat, dkk. 2016)

Dalam penelitian ini, dilakukan pengukuran candi Jawi menggunakan dua wahana yang berbeda yaitu quadcopter dan TLS untuk mengetahui perbandingan hasil model tiga dimensi kedua data ditinjau dari beberapa kriteria penilaian.

\section{METODE}

\section{Lokasi penelitian}

Lokasi penelitian dilakukan di situs Candi Jawi, yang terletak di Jalan Raya Prigen, Desa Candi Wates, Kecamatan Ngadilegi, Kabupaten Pasuruan, Jawa Timur dengan koordinat lokasi pada $7^{\circ} 39^{\prime} 45.0^{\prime \prime}$ Lintang Selatan (LS), 112 40' 3.9” Bujur Timur (BT), yang ditunjukkan oleh Gambar 1. Di situs candi ini dilakukan pengukuran terhadap point of interest (Pol) yaitu Candi Jawi, sebagai objek penelitian menggunakan wahana quadcopter dan TLS..

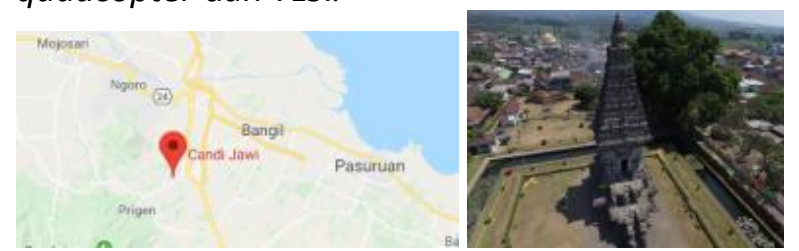

Gambar 1. Lokasi penelitian situs Candi Jawi

\section{Tahap Pengambilan data}

Dalam penelitian ini, pendekatan informasi posisi Candi Jawi menggunakan pengamatan Global Positioning System (GPS) geodetik pada titik-titik
Ground Control Point (GCP) yang disiapkan di sekitar bangunan Candi Jawi. Koordinat GCP yang diperoleh digunakan sebagai titik ikat yang memuat informasi koordinat dunia nyata (posisi sebenarnya di lapangan) (Ulinuha, Rifqi, 2016). Selanjutnya, dilakukan pengambilan data foto Candi Jawi dengan bantuan wahana quadcopter. Candi Jawi dipotret dari berbagai sisi dengan metode terbang orbital dan overlap tinggi (60$80 \%$ ). Selain pengambilan data GCP, perlu dilakukan pengambilan data titik-titik Independent Check Point (ICP) pada badan POI yang berfungsi sebagai titik bantu dalam mendefinisikan dimensi objek yang dimodelkan. Dilanjutkan dengan pengukuran Candi Jawi menggunakan TLS. Disekitar bangunan Candi Jawi diberi marker berupa benda bulat yang disebut dengan sphere sebagai objek penanda untuk menggabungkan data hasil scan (saat pengolahan data) setiap kali berdiri alat di suatu titik dengan hasil dari titik lain. Pengukuran dengan TLS dikerjakan di atas titik-titik GCP.

\section{Tahap Pengolahan data}

Hasil potret Candi Jawi menggunakan wahana quadcopter selanjutnya dibuatkan model tiga dimensinya melalui aplikasi pengolah data foto udara. Proses pengolahan meliputi aligning photos yaitu menyusun dan mesejajarkan foto yang bertampalan menggunakan interest point dari satu foto dan ditampalkan pada foto lain yang memuat interest point yang sama dikenal dengan istilah feature detection dan feature matching, build dense cloud yaitu ekstraksi piksel foto menjadi data vektor berupa titik-titik yang memuat informasi depth of field dari masing-masing foto, build mesh yaitu proses menyambungkan titik-titik pada point cloud sebagai penentu tipe permukaan objek, texturing yaitu proses pembuatan tekstur model mendekati objek nyata di lapangan.

Koordinat GCP dan ICP selanjutnya diinputkan pada data foto quadcopter sebagai titik ikat dan titik referensi. Nilai GCP berfungsi memberikan koordinat nyata di setiap piksel pada foto, sedangkan ICP sebagai titik referensi atau titik bantu pembentukan model sekaligus data pembanding ketelitian model tiga dimensi yang akan dibuat.

Hasil pengukuran TLS yang dilakukan secara bertahap digabungkan agar dapat membentuk suatu model utuh (Tilly, dkk. 2014). Proses 
penggabungan dilakukan dengan metode target based yaitu menampalkan posisi sphere yang terdeteksi pada hasil scan 2 ke scan 1 yang memuat sphere yang sama saat proses pengambilan data.

\section{HASIL DAN PEMBAHASAN}

\section{Ground Control Point (GCP) pengamatan GPS}

Untuk memperoleh informasi mendekati posisi riil Candi Jawi, dilakukanl pengamatan titik GCP di situs Candi Jawi dengan GPS Geodetik. Titik GCP yang diukur berjumlah 4 titik yang mengelilingi Candi Jawi. Titik GCP berada pada posisi yang tidak banyak dilewati oleh orang, kendaraan, dan tidak tertutup oleh bangunan atau benda lain. Gambar 2 berikut ini adalah sebaran posisi titik GCP Candi Jawi;

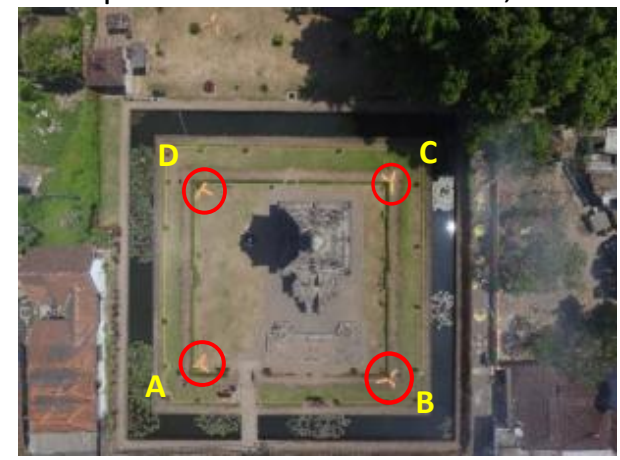

Gambar 2. Sebaran posisi titik GCP

Melalui pengamatan GPS diperoleh koordinat untuk masing-masing titik GCP yang memuat nilai Easting, Northing, serta Tinggi Orthometrik. Hasil tersebut ditunjukkan pada Tabel 1.

Tabel 1. Koordinat Titik GCP

\begin{tabular}{cccc}
\hline \hline Titik & Easting $(\mathrm{m})$ & Northing $(\mathrm{m})$ & Tinggi $(\mathrm{m})$ \\
\hline A & 684195,086 & 9152634,199 & 313,229 \\
B & 684210,872 & 9152652,922 & 313,234 \\
C & 684190,389 & 9152668,248 & 313,215 \\
D & 684176,694 & 9152647,705 & 313,342 \\
\hline \hline
\end{tabular}

Dengan nilai standar deviasi untuk masingmasing titik GCP pada Tabel 2.

Tabel 2. Standar Deviasi Pengamatan Titik GCP

\begin{tabular}{cccc}
\hline Titik & $\begin{array}{c}\text { Std dev } \\
\text { Northing } \\
(\mathrm{m})\end{array}$ & $\begin{array}{c}\text { Std dev } \\
\text { Easting } \\
(\mathrm{m})\end{array}$ & $\begin{array}{c}\text { Std dev } \\
\text { Height } \\
(\mathrm{m})\end{array}$ \\
\hline Base & 0,000 & 0,000 & 0,000 \\
A & 0,001 & 0,001 & 0,002
\end{tabular}

\begin{tabular}{llll} 
B & 0,001 & 0,001 & 0,003 \\
C & 0,006 & 0,004 & 0,008 \\
D & 0,001 & 0,001 & 0,003 \\
\hline
\end{tabular}

Perolehan nilai standar deviasi dalam pengamatan titik GCP mayoritas kecil, namun terdapat nilai yang cukup besar yaitu pada titik GCP $C$ untuk standar deviasi sebesar 0,006 meter, standar deviasi Easting sebesar 0,004 meter, dan standar deviasi Height sebesar 0,008 meter. Lihat Tabel 2.

Tabel 3. Informasi Jarak dan RMSe Titik GCP

\begin{tabular}{crcccc}
\hline \hline Name & $\begin{array}{r}\mathrm{dN} \\
(\mathrm{m})\end{array}$ & $\begin{array}{c}\mathrm{dE} \\
(\mathrm{m})\end{array}$ & $\begin{array}{c}\mathrm{dHt} \\
(\mathrm{m})\end{array}$ & $\begin{array}{c}\text { Horz } \\
\text { RMS } \\
(\mathrm{m})\end{array}$ & $\begin{array}{c}\text { Vert } \\
\text { RMS } \\
(\mathrm{m})\end{array}$ \\
\hline Base- A & $-27,116$ & 35,910 & 1,766 & 0,001 & 0,002 \\
Base- B & $-8,393$ & 51,695 & 1,771 & 0,002 & 0,003 \\
Base- C & 6,933 & 31,213 & 1,752 & 0,007 & 0,008 \\
Base-D & $-13,610$ & 17,518 & 1,779 & 0,001 & 0,003 \\
\hline \hline
\end{tabular}

Jarak posisi masing-masing titik GCP A, B, C dan $D$ terhadap Base dimuat pada Tabel 3, beserta besaran nilai RMSe-nya. Titik GCP C memuat nilai RMSe paling besar dan nilai standar deviasi paling besar (lihat Tabel 2) diantara titik GCP yang lain hal ini diduga disebabkan karena adanya faktor multipath dalam proses pengamatan titik GCP C. Dapat diperhatikan pada Gambar 2 yaitu posisi titik GCP $C$ bersebelahan dengan pohon beringin yang memiliki dimensi cukup besar.

\section{Independent Check Point (ICP) pengukuran dengan Total Station}

ICP berperan sebagai titik bantu atau titik referensi sekaligus digunakan sebagai pembanding ketelitian model tiga dimensi. Dalam penelitian ini, ICP yang digunakan berjumlah 22 titik. Berikut ini merupakan tabel koordinat ICP Candi Jawi, dapat dilihat pada Tabel 4.

Tabel 4. Koordinat Titik ICP

\begin{tabular}{ccccc}
\hline \hline No. & Titik & $X(\mathrm{~m})$ & $Y(\mathrm{~m})$ & $\mathrm{Z}(\mathrm{m})$ \\
\hline 1 & ICP 1 & 684197,468 & 9152649,455 & 315,410 \\
2 & ICP 2 & 684191,550 & 9152649,258 & 315,033 \\
3 & ICP 3 & 684196,963 & 9152650,697 & 318,263 \\
4 & ICP 4 & 684195,460 & 9152649,915 & 318,412 \\
5 & ICP 5 & 684191,505 & 9152649,673 & 318,358 \\
6 & ICP 6 & 684193,218 & 9152651,311 & 320,373 \\
7 & ICP 7 & 684191,259 & 9152651,442 & 326,068
\end{tabular}




\begin{tabular}{ccccc}
\hline No. & Titik & $X(\mathrm{~m})$ & $\mathrm{Y}(\mathrm{m})$ & $\mathrm{Z}(\mathrm{m})$ \\
\hline 8 & ICP 8 & 684198,757 & 9152651,233 & 315,434 \\
9 & ICP 9 & 684197,133 & 9152656,964 & 315,006 \\
10 & ICP 10 & 684197,979 & 9152651,582 & 318,178 \\
11 & ICP 11 & 684197,723 & 9152654,000 & 318,353 \\
12 & ICP 12 & 684196,731 & 9152656,921 & 318,357 \\
13 & ICP 13 & 684195,757 & 9152654,793 & 320,431 \\
14 & ICP 14 & 684195,083 & 9152656,634 & 326,029 \\
15 & ICP 15 & 684189,491 & 9152662,573 & 314,997 \\
16 & ICP 16 & 684189,550 & 9152662,051 & 318,349 \\
17 & ICP 17 & 684189,650 & 9152659,317 & 321,297 \\
18 & ICP 18 & 684189,896 & 9152660,438 & 326,080 \\
19 & ICP 19 & 684183,952 & 9152654,957 & 315,028 \\
20 & ICP 20 & 684187,608 & 9152658,098 & 319,373 \\
21 & ICP 21 & 684185,586 & 9152655,166 & 320,407 \\
22 & ICP 22 & 684186,073 & 9152655,238 & 326,076 \\
\hline \hline
\end{tabular}

\section{Model 3D data foto}

Pada tahap pengambilan foto Candi Jawi dari berbagai sisi baik dari tampak depan, samping kanan kiri, belakang, dan atas, jumlah foto keseluruhan yang diambil berjumlah 223 foto. Gambar 3 menunjukkan kumpulan foto tersebut.

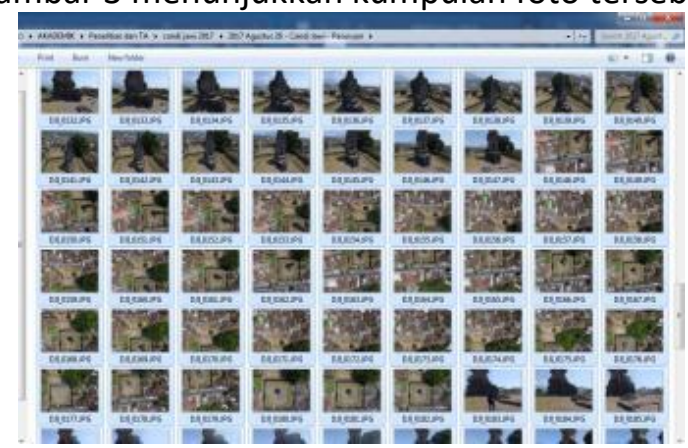

Gambar 3. Kumpulan foto Candi Jawi

Foto yang telah diperoleh tersebut kemudian dibuatkan model tiga dimensinya. Adapun tahapan dalam membuat model tiga dimensi Candi Jawi adalah sebagai berikut,

a. Aligning photos

Proses menyusun dan mensejajarkan foto yang memiliki interest point yang sama antar foto, yang dipengaruhi oleh tingkat overlap dan sidelap foto pada saat proses pengambilan data.

b. Build Dense Cloud

Proses ekstraksi depth of field yang didapat dari foto yang diubah menjadi sekumpulan titik untuk membentuk objek yang dipotret.

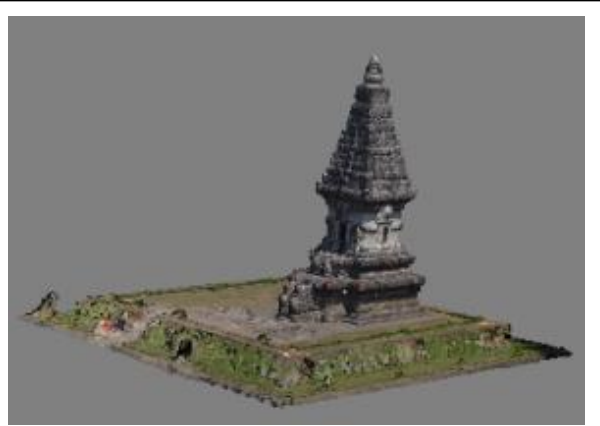

Gambar 4. Hasil Build Dense Cloud

a. Build Mesh

Proses ini bertujuan untuk membentuk tipe permukaan data yang akan dibangun.

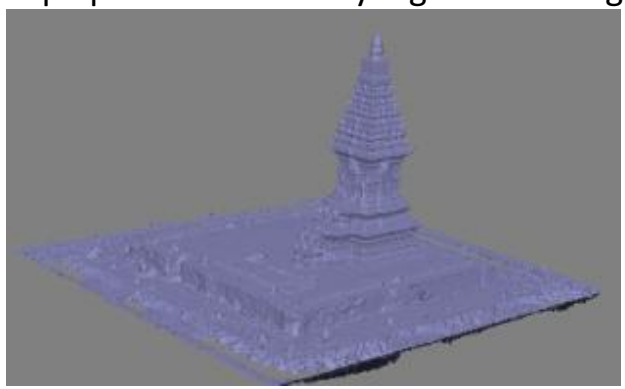

Gambar 5. Hasil Build Mesh

\section{b. Texturing}

Proses penentuan tekstur objek yang akan dikemas dan ditampilkan secara keseluruhan.

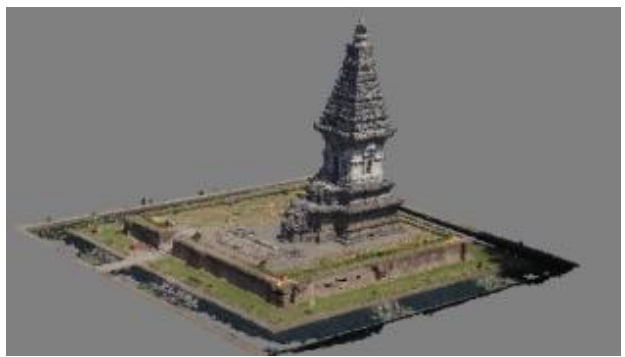

Gambar 6. Hasil Texturing

Hasil Geometri untuk semua titik tentang Point cloud, Build Mesh, dan Wireframe disusun pada Tabel 5.

\begin{tabular}{ll}
\multicolumn{2}{c}{ Tabel 5. Hasil Geometri } \\
\hline \hline Hasil & Geometri \\
\hline Point cloud & 11.487 titik \\
Build Mesh & 17.080 .488 titik \\
Wireframe & 514.603 faces, \\
& 260.087 vertices \\
\hline \hline
\end{tabular}

\section{Model 3D data pengukuran Laser Scanner}

Pengukuran Candi Jawi menggunakan Faro Focus 3D Laser Scanner dilakukan sebanyak 6 kali berdiri alat pada 6 titik, dengan posisi berdiri alat adalah sebagai berikut, lihat Gambar 7 , 


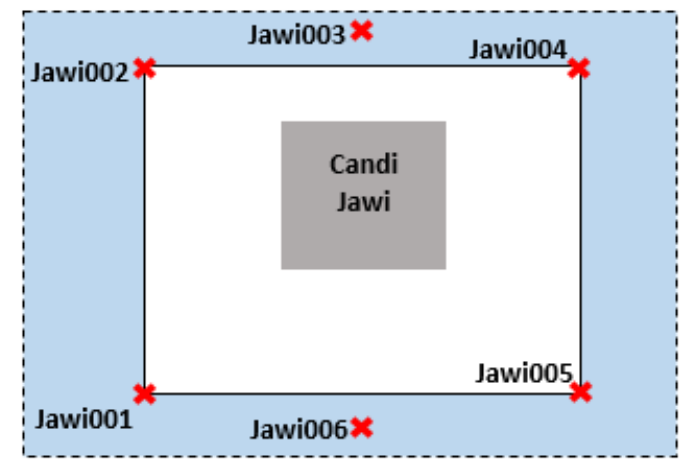

Gambar 7. Posisi berdiri alat TLS

Data pengukuran TLS berupa point cloud selanjutnya diolah agar dapat membentuk model tiga dimensi Candi Jawi. Tahapan pengolahan data TLS adalah alignment scene, yaitu hasil scanning setiap kali berdiri alat digabung menggunakan metode target based. Yang menjadi target adalah sphere yang disebar secara rata di lokasi pada saat proses pengambilan data dengan diperkirakan dapat masuk dalam daerah sapuan laser. Dilanjutkan dengan tahap registrasi dan transformasi koordinat model dengan cara memasukkan salah satu titik GCP ke salah satu posisi berdiri alat yang sesuai dengan titik GCP yang digunakan. Coloring, proses mewarnai model agar sesuai dengan kenampakan objek aslinya. Hasil scan objek, gabungan, dan hasil akhir dapat dilihat pada Gmbar 8,9 dan 10.

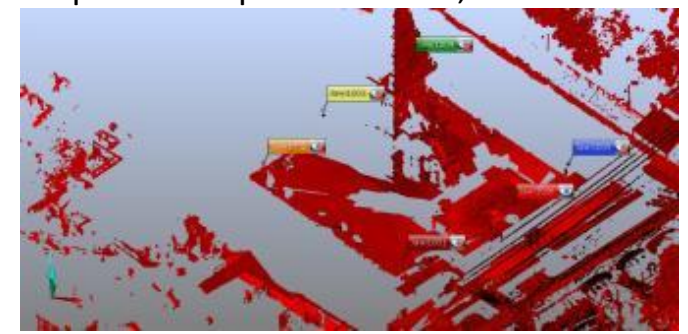

Gambar 8. Hasil scan pada titik Jawi006

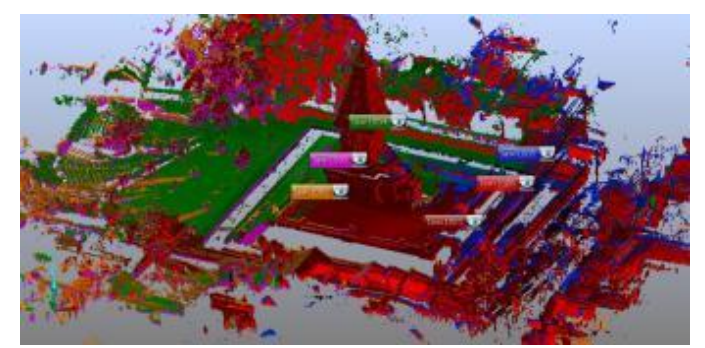

Gambar 9. Hasil gabungan semua scene

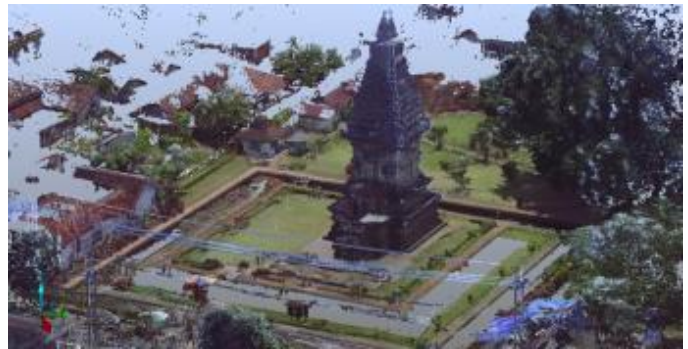

Gambar 10. Hasil akhir model 3D data TLS

\section{ANALISA}

\section{Analisis geometrik model tiga dimensi}

Analisis menggunakan titik ICP sebagai variabel pendekatan untuk melihat ketelitian model tiga dimensi Candi Jawi.Lihat Tabel 6.

Tabel 6 .Selisih Koordinat ICP Pengukuran Lapangan Dan ICP Model 3D Data Foto Quadcopter

\begin{tabular}{cccc}
\hline & \multicolumn{3}{c}{ Model-TS } \\
Titik & $\Delta x(\mathrm{~m})$ & $\Delta y(\mathrm{~m})$ & $\Delta z(\mathrm{~m})$ \\
\hline ICP 1 & 0.001 & 0.016 & 0.010 \\
ICP 2 & 0.006 & 0.005 & 0.003 \\
ICP 4 & 0.007 & 0.008 & 0.007 \\
ICP 5 & 0.012 & 0.013 & 0.010 \\
ICP 6 & 0.009 & 0.012 & 0.006 \\
ICP 7 & 0.009 & 0.017 & 0.014 \\
ICP 8 & 0.010 & 0.001 & 0.007 \\
ICP 9 & 0.019 & 0.017 & 0.010 \\
ICP 10 & 0.005 & 0.007 & 0.002 \\
ICP 11 & 0.002 & 0.001 & 0.012 \\
ICP 12 & 0.013 & 0.016 & 0.013 \\
ICP 13 & 0.035 & 0.020 & 0.066 \\
ICP 14 & 0.003 & 0.002 & 0.007 \\
ICP 15 & 0.016 & 0.010 & 0.007 \\
ICP 16 & 0.009 & 0.026 & 0.010 \\
ICP 18 & 0.002 & 0.007 & 0.015 \\
ICP 19 & 0.051 & 0.055 & 0.017 \\
ICP 21 & 0.016 & 0.005 & 0.010 \\
ICP 22 & 0.001 & 0.009 & 0.001 \\
\hline RMSe & 0.017 & 0.017 & 0.018 \\
\hline \hline
\end{tabular}

Pada Tabel 3 dapat dilihat masing-masing nilai RMSe untuk kelompok selisih $X$ adalah 0,017 meter, selisih $Y$ adalah 0,017 meter, dan selisih $Z$ sebesar 0,018 meter. Ketiga nilai RMSe tersebut merupakan nilai yang kecil karena berada pada rentang nilai kurang dari 2 sentimeter. 
Tabel 7. Tabel Selisih Koordinat ICP Pengukuran Lapangan Dan ICP Model 3D Data Point Cloud TLS TLS-TS

\begin{tabular}{crrr} 
Titik & $\Delta x(\mathrm{~m})$ & $\Delta y(\mathrm{~m})$ & $\Delta z(\mathrm{~m})$ \\
\hline ICP 1 & 0.049 & 0.017 & 1.465 \\
ICP 2 & 0.036 & 0.004 & 1.475 \\
ICP 4 & 0.015 & 0.014 & 1.478 \\
ICP 5 & 0.008 & 0.028 & 1.470 \\
ICP 6 & 0.015 & 0.027 & 1.528 \\
ICP 7 & 0.015 & 0.088 & 1.312 \\
ICP 8 & 0.031 & 0.002 & 1.472 \\
ICP 9 & 0.042 & 0.016 & 1.483 \\
ICP 10 & 0.037 & 0.008 & 1.475 \\
ICP 11 & 0.110 & 0.994 & 1.457 \\
ICP 12 & 0.056 & 0.008 & 1.471 \\
ICP 13 & 0.091 & 0.033 & 1.558 \\
ICP 14 & 0.019 & 0.063 & 1.327 \\
ICP 15 & 0.065 & 0.040 & 1.469 \\
ICP 16 & 0.117 & 0.004 & 1.485 \\
ICP 18 & 0.009 & 0.053 & 1.465 \\
ICP 19 & 0.114 & 0.094 & 1.464 \\
ICP 21 & 0.073 & 0.015 & 1.469 \\
ICP 22 & 0.055 & 0.005 & 1.473 \\
\hline RMSe & 0.061 & 0.231 & 1.464 \\
\hline \hline
\end{tabular}

Tabel 7 memuat nilai selisih antara koordinat ICP hasil pengukuran dengan nilai ICP model 3D data point cloud TLS. Nilai RMSe untuk masingmasing kelompok berdasarkan sumbu ternyata lebih besar daripada RMSe yang dihasilkan dari selisih ICP pengukuran dengan model dari data foto. Untuk selisih X pada Tabel 7 sebesar 0,061 meter, selisih $Y$ sebesar 0,231 meter, dan selisih $Z$ mencapai nilai 1,464 meter.

Terkait ketelitian model melalui analisis RMSe, model bangunan adalah sebuah konsep tematik dalam CityGML (City Geographic Markup Language) yang memungkinkan representasi aspek spasial dan tematik suatu bangunan, bagian bangunan, dan instalasi pada empat tingkat LoD'. Fokus penelitian ini adalah model eksterior dari POI, maka salah satu syarat akurasinya adalah LoD 3 dengan nilai RMSe 0,5 meter. Sedangkan besaran RMSe yang diperoleh dalam penelitian ini untuk selisih ICP pengukuran dengan ICP TLS pada sumbu Z melebihi ketetapan tersebut. Adapun sebab dari hal ini diperkirakan yaitu ketika proses picking point pada data TLS yang melibatkan interpretasi manusia sebagai pengguna rawan kesalahan (human error), kondisi alat TLS yang digunakan yaitu belum dilakukannya kalibrasi alat diduga mempengaruhi hasil pengukuran lapangan sehingga ketika dilakukan georefencing faktor penyebab kesalahan tetap terbawa. Penyebab alat TLS tidak dikalibrasi oleh pemilik alat dikarenakan dikenakan biaya kalibrasi yang mahal.

\section{Analisis waktu}

Tabel 8. berikut ini disajikan waktu kasaran yang dihabiskan dalam memodelkan Candi Jawi jika dikerjakan menurut 2 cara, yaitu jika memodelkan Candi Jawi menggunakan data foto wahana quadcopter dan data point cloud TLS diikuti proses pengukuran pendukung.

Tabel 8. Estimasi Waktu Pengerjaan Model 3D Data Wahana Quadcopter \& TLS

\begin{tabular}{|c|c|c|c|}
\hline No. & Pembanding & Quadcopter & $T L S$ \\
\hline 1 & $\begin{array}{l}\text { Perjalanan menuju } \\
\text { lokasi }\end{array}$ & $120 \mathrm{~min}$ & $120 \mathrm{~min}$ \\
\hline 2 & Setting alat & $20 \mathrm{~min}$ & $20 \mathrm{~min}$ \\
\hline 3 & Pengamatan titik GCP & $120 \min$ & $120 \mathrm{~min}$ \\
\hline 4 & $\begin{array}{l}\text { Pengambilan data } \\
\text { candi }\end{array}$ & $30 \mathrm{~min}$ & $90 \mathrm{~min}$ \\
\hline 5 & Pengukuran titik ICP & $240 \min$ & \\
\hline 6 & Pengolahan titik GCP & $20 \mathrm{~min}$ & $20 \mathrm{~min}$ \\
\hline 7 & Pengolahan titik ICP & $20 \mathrm{~min}$ & $20 \mathrm{~min}$ \\
\hline \multirow[t]{2}{*}{8} & $\begin{array}{l}\text { Pengolahan data } \\
\text { candi }\end{array}$ & $480 \mathrm{~min}$ & $900 \mathrm{~min}$ \\
\hline & Total & $1070 \mathrm{~min}$ & $\begin{array}{l}1290 \\
\min \end{array}$ \\
\hline
\end{tabular}

Berdasarkan Tabel 8 meliputi pengambilan dan pengolahan data, waktu yang dibutuhkan dalam membuat model tiga dimensi Candi Jawi lebih singkat jika dikerjakan dengan menggunakan data foto yang dipotret menggunakan wahana quadcopter.

\section{Analisis biaya}

Kisaran harga dalam sub bab analisis biaya berikut ini mengikuti harga sewa alat yang disediakan oleh Laboratorium Geodesi dan Surveying Teknik Geomatika ITS, tidak mengikuti harga sewa alat di tempat lain (kecuali alat TLS mengikuti harga sewa normal PT. EXSOL Trimitra selaku pemilik alat) karena analisis biaya ini bertujuan agar dapat menjadi gambaran anggaran dana pengukuiran. Estimasi biaya pada Tabel 9 dibawah ini belum termasuk biaya tambahan jika 
menghadirkan tenaga ahli atau supervisor lapangan.

Tabel 9. Estimasi Anggaran Minimal Pengambilan

Data Pembuatan Model 3D Candi Jawi Dengan Wahana Quadcopter Dan TLS

\begin{tabular}{|c|c|c|c|}
\hline No. & Keterangan & $\begin{array}{c}\text { Quadcopter } \\
\text { (Rp dalam } \\
\text { ribu) }\end{array}$ & $\begin{array}{c}T L S \\
\text { (Rp dalam } \\
\text { ribu) }\end{array}$ \\
\hline 1 & $\begin{array}{l}\text { Sewa mobil } \\
\text { ( } 1 \text { unit ) }\end{array}$ & 250 & 250 \\
\hline 2 & $\begin{array}{l}\text { GPS } \\
\text { Geodetik } \\
\text { ( } 3 \text { unit ) }\end{array}$ & 1.500 & 1.500 \\
\hline 3 & $\begin{array}{l}\text { Total } \\
\text { Station } \\
\text { ( } 1 \text { unit ) }\end{array}$ & 250 & - \\
\hline 4 & $\begin{array}{l}\text { Quadcopter } \\
\text { (1 unit) + } \\
\text { operator }\end{array}$ & 3.000 & - \\
\hline 5 & $\begin{array}{l}\text { Terestrial } \\
\text { Laser } \\
\text { Scanner } \\
\text { ( } 1 \text { unit )+ } \\
\text { operator }\end{array}$ & & 5.000 \\
\hline 6 & $\begin{array}{l}\text { Pengolahan } \\
\text { data }+ \\
\text { analisis }\end{array}$ & 1.500 & 25.000 \\
\hline & Total & 7.500 & 31.750 \\
\hline
\end{tabular}

(catatan : harga bervariasi)

Dari total biaya pada Tabel 9, dapat dilihat bahwa pengambilan data Candi Jawi menggunakan alat TLS membutuhkan dana yang lebih mahal daripada menggunakan wahana quadcopter.

\section{Format data}

Format atau ekstensi data sangat mempengaruhi ukuran file, terdapat perbedaan ukuran file yang signifikan. Penyebabnya adalah perbedaan tipe data. Pada data foto terdiri atas piksel citra foto yang kemudian menjadi point cloud, wireframe, vertices, dan tekstur. Sementara pada TLS data yang terekam sejak awal sudah dalam wujud point cloud yang menghabiskan space memory lebih banyak.Lihat Tabel 10.
Tabel 10. Format Data Olahan Quadcopter dan Data TLS

\begin{tabular}{ccc}
\hline Aspek & Quadcopter & TLS \\
\hline $\begin{array}{c}\text { format } \\
\text { data }\end{array}$ & .psz, .obj & .pts, .obj, \\
ukuran file & $13,8 \mathrm{Mb}$ & $6 \mathrm{~GB}$ \\
\hline
\end{tabular}

\section{KESIMPULAN}

Adapun kesimpulan yang diperoleh berdasarkan penelitian ini adalah sebagai berikut:

1. Telah dibuat model 3D Candi Jawi menggunakan data foto dan point cloud yang diakusisi dengan wahana quadcopter dan TLS.

2. Perbandingan geometri model 3D Candi Jawi menggunakan nilai RMSe ICP sebagai variabel pendekatan ketelitian model. Pada model data berniali masing-masing $\mathrm{X}, \mathrm{Y}$, dan $\mathrm{Z}$ yaitu 0,017 $\mathrm{m}, 0,018 \mathrm{~m}$, dan $0,018 \mathrm{~m}$. sementara dengan hasil picking point posisi ICP data model3D TLS nilai RMSe $X, Y$, dan $Z$ sebesar 0.061 meter, 0.231 meter, dan 1.464 meter. Nilai RMSe Z yang belum mencukupi tingakt $L O D 3$ yaitu syarat model bangunan dalam konsep CityGML yang diperuntukkan visualisasi eksterior bangunan yang bernilai di bawah 0,5 meter ( $L O D 3)$.

3. Berdasarkan analisis, pemodelan 3D Candi Jawi dari segi biaya, waktu, dan format data pembuatan model 3D Candi Jawi dengan data foto quadcopter relatif lebih murah, cepat, dan hemat ruang memori bila dibandingkan dengan data point cloud TLS.

\section{UCAPAN TERIMA KASIH}

LPPM ITS, PT. EXSOL Trimitra, PT. NPC Laboratorium

\section{DAFTAR PUSTAKA}

Sutopo, M. 2014. "Merekam Jejak Masa Lalu Cagar Budaya Dalam Perspektif 3D". Magelang: Balai Konservasi Borobudur Direktorat Jenderal Kebudayaan Kementerian Pendidikan dan Kebudayaan.

Hidayat dkk. 2016. "Combined aerial and terestrial images for 3D documentation of Singosari Temple based on Structure from Motion algorithm". Proceeding ICOIRS 2016.

Ulinnuha, Rifqi. 2016. “Analisa Ketelitian dan Kesesuaian Pemodelan 3D Dengan Pendekatan Geometri dan Teknik Structure from Motion (SFM) pada Obyek 
Bangunan". Surabaya: Institut Teknologi Sepuluh Nopember.

Tilly, dkk. 2014. "Multitemporal crop surface models: Accurate plant height measurement and biomass estimation with terestrial laser scanning in paddy rice". Journal of Applied Remote Sensing. 